\title{
The role of probiotics in preventing necrotizing enterocolitis and reducing mortality in neonates: a meta-analysis
}

\author{
Yu-qing Pan \\ Shengjing Hospital of China Medical University \\ A-na Hou \\ Shengjing Hospital of China Medical University \\ Xin-dong Xue \\ Shengjing Hospital of China Medical University \\ Jian-hua Fu ( $\sim$ fujh77@163.com ) \\ China Medical University
}

\section{Research article}

Keywords: Necrotizing enterocolitis; Probiotic; Neonate; Meta-analysis

Posted Date: September 2nd, 2019

DOl: https://doi.org/10.21203/rs.2.13872/v1

License: (1) This work is licensed under a Creative Commons Attribution 4.0 International License. Read Full License 


\section{Abstract}

Background: Probiotics are gradually being used as a supplementation to prevent necrotizing enterocolitis (NEC) and reduce mortality in neonates. We performed an updated meta-analysis to systematically evaluate the efficacy and safety of prophylactic probiotic supplementation for preventing NEC. Methods: The databases including PubMed, EMbase, and China National Knowledge Infrastructure were used to search the relevant articles. The latest retrieval date was up to May 2019. Two reviewers independently screened literature, extracted data, and assessed the risk of bias of the included studies. The meta-analysis was performed using Stata version 10.0. Results: Finally, a total of 74 studies containing - cases and - controls were included. The results showed that the probiotics could significantly reduce the incidence of NEC (stage II or more) $(\mathrm{OR}=0.435,95 \% \mathrm{Cl}=0.357-0.530, \mathrm{p}<0.001)$, the overall mortality $(\mathrm{OR}=0.630,95 \% \mathrm{Cl}=0.491-0.808$, $\mathrm{p}<0.001)$, and NEC-related mortality $(\mathrm{OR}=0.639,95 \% \mathrm{Cl}=0.423-0.966, \mathrm{p}=0.034)$. Conclusion: This metaanalysis indicates that the use of probiotics can effectively reduce the occurrence of NEC and mortality in neonates. These data provide the possible information for the clinical treatment.

\section{Background}

Necrotizing enterocolitis (NEC) is one of the potentially catastrophic illness of neonate with a high morbidity of up to $10 \%$ and a mortality of $20-30 \%$ in developed countries ${ }^{1-3}$. It usually has the clinically significant long- and short-term consequences. Nearly one-third to one-half of NEC patients require surgery ${ }^{4}$. The infant recovering from NEC may has a $25 \%$ chance of microcephaly and serious neurodevelopmental delays ${ }^{5}$. Additionally, the financial cost of NEC is substantial with the annual cost from $\$ 500$ million to $\$ 1$ billion in the United States ${ }^{1}$.

The etiology of NEC is not fully understood and various mechanisms have been considered to contribute to its development. Its incidence is relatively rare in unfed newborns. The risk factors include fetal distress and perinatal events after births, such as hypothermia, congenital heart disease, and sepsis ${ }^{4}$. The main factors thought to be involved in the pathogenesis of NEC are intestinal immaturity, enteral feeds, the intestinal microbiome, inflammation, and local ischaemia and/or reperfusion injury ${ }^{6}$.

Some dietary has been suggested to prevent the incidence of NEC. Lactoferrin, is found in human breast milk. As a glycoprotein, it can participate the formation of innate immune response and reduce the sepsis in infants after oral human lactoferrin ${ }^{7}$. A randomized controlled trial (RCT) showed that bovine lactoferrin reduced the occurrence of NEC and the risk of death ${ }^{8}$. Recently, the effect of probiotics on the prevention of NEC has attracted many attentions. A lot of RCTs and cohort studies have reported that the supplementation of probiotics can reduce the incidence of NEC ${ }^{9}$. However, the inadequate sample size limits their value. There is still no sufficient evidence to recommend the routine administration of probiotics. Moreover, the optimum probiotic species or strains, duration of treatment, and its interaction with diet are also undetermined ${ }^{9}$. Meta-analysis is a widely used statistical method in medical studies, particularly for a topic that are being extensively studied with controversial results ${ }^{10}$. Thus, we performed a meta-analysis of studies examining the role of probiotics in preventing NEC and decreasing mortility to provide a more comprehensive assessment. 


\section{Methods}

Identification and eligibility of relevant studies

To identify studies eligible for inclusion in this meta-analysis, three online electronic databases (PubMed, EMbase, and China National Knowledge Infrastructure) were searched (the last search update was 2019 May). The following key words were used in the literature search: probiotics, necrotizing enterocolitis, necrotizing enterocolitis, or NEC. Reference lists from identified articles and potentially relevant review articles were also screened to identify additional studies. Studies met the following inclusion criteria: the intervention was the probiotic supplementation to the intervention group, the control was a control or placebo group that did not receive probiotic supplementation, and the outcomes included NEC (stage $\geq 2)^{11}$, mortality, or NEC-related mortality. The participants included both of preterm and term neonates.

\section{Data extraction}

Based on the inclusion criteria, two reviewers (Yu-ping Pan and A-na Hou) independently extracted information from all eligible publications. Disagreements were resolved through discussion until the two reviewers reached a consensus. The following data were included from each study: first author's last name, publication year, country, probiotic strains, and number of NEC, mortality, or NEC-related mortality between cases and controls.

Statistical analysis

All statistical tests were two-sided, and $p<0.05$ was considered statistically significant. The meta-analysis was performed using Stata version 10.0 (Stata Corp., College Station, TX). The strength of the association between the supplementation of probiotics and NEC was measured by odd ratios (ORs) with $95 \%$ confidence intervals (Cls). Pooled effect sizes across studies were performed by a random effect model, which evaluates the likely effect size across different populations and takes heterogeneity across studies into account. This model is different from a fixed effects model, which evaluates the most likely effect size from multiple studies by hypothesizing that they are sampled from a single population, but the model can be biased by high heterogeneity across studies ${ }^{12}$.

The degree of heterogeneity between studies was determined by Q-statistic ${ }^{13,14}$. P $>0.05$ for the Q-test indicated a lack of heterogeneity and $p<0.05$ indicated heterogeneity. $\mathrm{I}^{2}$ is the proportion of observed variance in effect sizes attributable to the true differences among studies. Conventional interpretations of $\mathrm{I}^{2}$ define limits for low (<25\%), moderate ( $50 \%)$, and high $(>75 \%)$ heterogeneity 15 .

An estimate of publication bias was performed by visual inspection of a funnel plot in which the standard error of $\log (\mathrm{OR})$ of each study was plotted against its log (OR). An asymmetric plot indicated possible publication bias, and the degree of asymmetry was tested using Egger's test $(p<0.05$ indicated significant publication bias) ${ }^{16}$.

Sensitivity analysis was performed to assess the potential influences of a single study on the pooled effect size. It was performed by omitting single studies one at a time for each meta-analysis to screen for 
significant alterations to pooled effect size.

\section{Results}

After the removal of overlapping articles and those that did not meet the inclusion criteria, a total of 68 articles were finally included ${ }^{8,17-83}$. Seventy three studies with 8472 cases and 9431 controls investigated probiotics for the prevention of NEC. Forty studies with 6410 cases and 7717 controls investigated probiotics for the reducing of mortality. Seventeen studies with 3004 cases and 3002 controls investigated probiotics for the reducing of NEC-related mortality. The key characteristics of the studies were showed in Table 1.

Quantitative synthesis and heterogeneity analysis

We analyzed 70 studies regarding the role of probiotics in preventing NEC after three studies were removed without the available calculated data (Table 2). The pooled results indicate that there was an association between probiotics and the occurrence of NEC under random effects model $(\mathrm{OR}=0.435,95 \% \mathrm{Cl}=0.357-$ $0.530, p<0.001$ ) (Fig. 1). The heterogeneity test showed that the degree of heterogeneity was statistically significant $\left(p=0.006 ; 1^{2}=32.5 \%\right)$.

A total of 38 studies explored the association between probiotics and incidence of mortality after removing two studies without the available calculated data (Table 2). The pooled results indicate that there was an association between probiotics and the risk of mortality under random effects model $(\mathrm{OR}=0.630,95 \% \mathrm{Cl}=$ $0.491-0.808, p<0.001$ ) (Fig. 2). The heterogeneity test showed that the degree of heterogeneity was statistically significant $\left(p<0.001 ; 1^{2}=52.0 \%\right)$.

There were 16 studies concerning the association of probiotics with the risk of NEC-related mortality after one study was removed without the available calculated data (Table 2). The meta-analysis showed that the supplementation of probiotics could decrease the incidence of NEC-related mortality under random effects model $(\mathrm{OR}=0.639,95 \% \mathrm{Cl}=0.423-0.966, p=0.034)$ (Fig. 3). The heterogeneity test showed that there was no significant heterogeneity $\left(p=0.525 ; 1^{2}=0.0 \%\right)$.

Cumulative meta-analysis

Cumulative meta-analysis was performed according to published date in chronological order using the random model. No continuous trend toward a significant association with a more narrowing $95 \% \mathrm{Cl}$ was presented as studies published by year.

Sensitivity analysis

Sensitivity analysis was performed for each meta-analysis to assess the influence of every single study. Corresponding pooled ORs showed no significant change when one study was removed at a time from each meta-analysis, indicating that these results are stable and reliable.

Publication bias 
The funnel plots were generated to assess potential publication bias (Fig. 4-6). Egger's tests were used to supply statistical evidence for funnel plot symmetry. The results showed that there was publication bias existing in the studies about NEC incidence and overall mortality ( $p<0.001$ and $p=0,023$, respectively), while the result of NEC-related mortality did not show any evidence of publication bias $(p=0.621)$.

\section{Discussion}

The present meta-analysis included 73 studies to explore the association between probiotics and the incidence of NEC, overall mortality, and NEC-related mortality. The final pooled results showed that the supplementation of probiotic bacteria could effectively prevent the occurrence of NEC, overall mortality, and NEC-related mortality. Cumulative meta-analysis and sensitivity analysis strengthened the validity of the results. There were significant heterogeneity in the meta-analysis of the role of probiotics in the incidence of NEC and overall mortality. It may be due to the differences in species, dose and time of administration, complications, et al ${ }^{84}$. The results need to be interpreted cautiously. Additionally, there are many reviews and meta-analysis to investigate the association between probiotic supplementation and the occurrence of NEC and mortality. To some extent, our present meta-analysis seems superfluous and unnecessary. However, after screening the databases in English and Chines, our pooled analysis included a total of 73 studies with 8472 cases and 9431 controls investigating probiotics for the prevention of NEC, 40 studies with 6410 cases and 7717 controls investigating probiotics for the reducing of mortality, and 17 studies with 3004 cases and 3002 controls investigating probiotics for the reducing of NEC-related mortality. The results with the large sample size can provide more reliable reference for the future study.

Previously, several meta-analysis reported the association between probiotics and NEC. Zhu et al. found that bifidobacterium may benefit the prevention of NEC in preterm infant ${ }^{85}$. Thomas et al. reported that the usage of probiotics could reduce the incidence of NEC and mortality in very low-birth-weight infants ${ }^{86}$. The similar results were found in very preterm infants ${ }^{84,87}$. Thus, our present meta-analysis included both of preterm and term neonates.

The mechanism by which probiotics reduce the incidence of NEC may be to prevent the growth of bacteria and the production of bacterial toxin by cleaning intestinal bacteria ${ }^{88}$. The recent study has reported that inflammation is one of the most important factors in the process of NEC. The activation of Toll-like receptor 4 (TLR4) inflammatory signaling pathway can give rise to the excessive inflammatory response ${ }^{89}$. Moreover, another study reported that the 72-h survival rate of experimental NEC in the formula-fed group was $56.3 \%$, but it increased to $86.7 \%$ after administrating Bifidobacterium adolescentis. The improvement might be related to the alteration of TLR4 expression ${ }^{90}$. In addition, Bifidobacterium can inhibit the secretion of proinflammatory cytokine to enhance intestinal barrier function ${ }^{91}$. The administration of Bifidobacterium significantly reduced the occurrence and development of NEC or mortality ${ }^{85}$. However, the suitable strain types, dosage, and forms (i.e., breast milk, preterm formula, and formula) are still undermined. A randomised controlled phase 3 trial did not support the routine use of probiotic Bifidobacterium breve BBG-001 for prevention of NEC, suggesting that this bifidobacterium alone was not the optimal agent to use ${ }^{59}$. Another study showed that a small dosage of probiotics $\left(<10^{9} \mathrm{CFU} / \mathrm{d}\right)$ significantly reduced the incidence of NEC and 
mortality and shorten hospital stay ${ }^{87}$, while the other study suggested that probiotics were more effective when taken in breast milk or breast milk plus formula form, at a dosage of $<10^{9} \mathrm{CFU} / \mathrm{d}$, and containing multiple strains ${ }^{87}$. However, a randomized clinical trial reported that the incidence of NEC was similar between single strain group and multispecies probiotic group ( $0 \%$ vs. $2.2 \%)^{92}$. Presently, no sufficient evidence recommended the optimal administration of probiotics in the clinical prevention of NEC. More studies are needed to explore the effects of probiotic in the risk of NEC and death.

There are several potential limitations to the present study. First, there was significant heterogeneity in the analyses. The pooled results need to be interpreted cautiously. There are other unknown aspects partially contributing to heterogeneity. Second, due to the lack of sufficient sample size, we did not performed the subgroup by types of probiotic strain and feeding to analyze the effects of bacterium in detail. Finally, we did not consider the impacts of neonatal birth status, weight and other complications on the outcomes.

\section{Conclusion}

In summary, our findings showed that the supplementation of probiotic bacteria could effectively prevent the occurrence of NEC, overall mortality, and NEC-related mortality. Cumulative meta-analysis and sensitivity analysis strengthened the validity of the results. More relevant studies are needed to validate our finding and provide the reference for clinical prevention and treatment of NEC.

\section{Abbreviations}

NEC: Necrotizing enterocolitis; RCT: randomized controlled trial; ORs: Odds ratios; Cls: confidence interval.

\section{Declarations}

\section{Ethics approval and consent to participate}

Not applicable

\section{Consent for publication}

Not applicable

\section{Availability of data and materials}

The datasets used and/or analyzed during the current study are available from the corresponding author on reasonable request.

\section{Competing interests}


The authors declare that they have no competing interests.

\section{Funding}

Not applicable

\section{Authors' contributions}

YQP participated in the design of the study and performed the statistical analysis. ANH and XDX exacted the key information and drafted the manuscript. JHF conceived the study and participated in its design and coordination. All authors contributed toward the drafting and revising of the final manuscript.

\section{Acknowledgements}

Not applicable

\section{References}

1.Neu J, Walker WA. Necrotizing enterocolitis. The New England journal of medicine. Jan 20 $2011 ; 364(3): 255-264$.

2.Obladen M. Necrotizing enterocolitis-150 years of fruitless search for the cause. Neonatology. 2009;96(4):203-210.

3.Holman RC, Stoll BJ, Curns AT, Yorita KL, Steiner CA, Schonberger LB. Necrotising enterocolitis hospitalisations among neonates in the United States. Paediatric and perinatal epidemiology. Nov 2006;20(6):498-506.

4.Rich BS, Dolgin SE. Necrotizing Enterocolitis. Pediatrics in review. Dec 2017;38(12):552-559.

5.Bedrick AD. Necrotizing enterocolitis: neurodevelopmental "risky business". Journal of perinatology: official journal of the California Perinatal Association. Sep 2004;24(9):531-533.

6.Eaton S, Rees CM, Hall NJ. Current Research on the Epidemiology, Pathogenesis, and Management of Necrotizing Enterocolitis. Neonatology. 2017;111(4):423-430.

7.Akin IM, Atasay B, Dogu F, et al. Oral lactoferrin to prevent nosocomial sepsis and necrotizing enterocolitis of premature neonates and effect on T-regulatory cells. American journal of perinatology. Dec 2014;31(12):1111-1120.

8.Manzoni P, Meyer M, Stolfi I, et al. Bovine lactoferrin supplementation for prevention of necrotizing enterocolitis in very-low-birth-weight neonates: a randomized clinical trial. Early human development. Mar 2014;90 Suppl 1:S60-65. 
9.Underwood MA. Impact of probiotics on necrotizing enterocolitis. Seminars in perinatology. Feb 2017;41(1):41-51.

10.Yang B, Fan S, Zhi X, et al. Associations of MTHFR gene polymorphisms with hypertension and hypertension in pregnancy: a meta-analysis from 114 studies with 15411 cases and 21970 controls. PloS one. 2014;9(2):e87497.

11.Bell MJ, Ternberg JL, Feigin RD, et al. Neonatal necrotizing enterocolitis. Therapeutic decisions based upon clinical staging. Annals of surgery. Jan 1978;187(1):1-7.

12.Munafo MR, Flint J. Meta-analysis of genetic association studies. Trends in genetics: TIG. Sep 2004;20(9):439-444.

13.Higgins JP, Thompson SG, Deeks JJ, Altman DG. Measuring inconsistency in meta-analyses. Bmj. Sep 6 2003;327(7414):557-560.

14.Zintzaras E, loannidis JP. Heterogeneity testing in meta-analysis of genome searches. Genetic epidemiology. Feb 2005;28(2):123-137.

15.Higgins JP, Thompson SG. Quantifying heterogeneity in a meta-analysis. Statistics in medicine. Jun 15 2002;21(11):1539-1558.

16.Egger M, Davey Smith G, Schneider M, Minder C. Bias in meta-analysis detected by a simple, graphical test. Bmj. Sep 13 1997;315(7109):629-634.

17.Underwood MA, Salzman NH, Bennett SH, et al. A randomized placebo-controlled comparison of 2 prebiotic/probiotic combinations in preterm infants: impact on weight gain, intestinal microbiota, and fecal short-chain fatty acids. Journal of pediatric gastroenterology and nutrition. Feb 2009;48(2):216-225.

18. Hikaru U, Koichi S, Yayoi S, et al. Bifidobacteria prevents preterm infants from developing infection and sepsis. International Journal of Probiotics \& Prebiotics. 2010;5(1):33-36.

19.Manzoni P, Rinaldi M, Cattani S, et al. Bovine lactoferrin supplementation for prevention of late-onset sepsis in very low-birth-weight neonates: a randomized trial. Jama. Oct 7 2009;302(13):1421-1428.

20.Sari FN, Eras Z, Dizdar EA, et al. Do oral probiotics affect growth and neurodevelopmental outcomes in very low-birth-weight preterm infants? American journal of perinatology. Sep 2012;29(8):579-586.

21.Kitajima H, Sumida Y, Tanaka R, Yuki N, Takayama H, Fujimura M. Early administration of Bifidobacterium breve to preterm infants: randomised controlled trial. Archives of disease in childhood. Fetal and neonatal edition. Mar 1997;76(2):F101-107.

22.Costalos C, Skouteri V, Gounaris A, et al. Enteral feeding of premature infants with Saccharomyces boulardii. Early human development. Nov 2003;74(2):89-96. 
23.Kanic Z, Micetic Turk D, Burja S, Kanic V, Dinevski D. Influence of a combination of probiotics on bacterial infections in very low birthweight newborns. Wiener klinische Wochenschrift. Dec 2015;127 Suppl 5:S210215.

24.Chou IC, Kuo HT, Chang JS, et al. Lack of effects of oral probiotics on growth and neurodevelopmental outcomes in preterm very low birth weight infants. The Journal of pediatrics. Mar 2010;156(3):393-396.

25.Van Niekerk E, Nel DG, Blaauw R, Kirsten GF. Probiotics Reduce Necrotizing Enterocolitis Severity in HIVexposed Premature Infants. Journal of tropical pediatrics. Jun 2015;61(3):155-164.

26.Samanta M, Sarkar M, Ghosh P, Ghosh J, Sinha M, Chatterjee S. Prophylactic probiotics for prevention of necrotizing enterocolitis in very low birth weight newborns. Journal of tropical pediatrics. Apr 2009;55(2):128-131.

27.Stratiki Z, Costalos C, Sevastiadou S, et al. The effect of a bifidobacter supplemented bovine milk on intestinal permeability of preterm infants. Early human development. Sep 2007;83(9):575-579.

28.Deng Maowen CQ. Clinical efficacy of glutamine combined with probiotics in preventing necrotizing enterocolitis in low-birth-weight neonates. Journal of Southwest Medical University. 2018;41(5):427-430.

29.Li Yingying HQ, Zhu Feng, Chai Yanyan, Liu Xiang IEl. Clinical observation of oral probiotics on prevention of necrotizing enterocolitis in very low birth weights. Anhui Medical Journal. 2014;35(9):1210-1212.

30.Liao Zhenyu HR, Xiao Aiqing. Effect of Bifid Triple Viable Capsules on Feeding Intolerance in Low Birth Weight Premature Infants. Journal of Pediatric Pharmacy. 2013;19(3):9-12.

31.Zeng Shuangzhi YP, Jiang Xin. The validity analysis of minimal feeding combined with probiotics siliankang in preventing necrotizing enterocolitis of preterm infant. China Medical Engineering. 2014;22(10):8-9, 11.

32.Hu Xiaoyan ZY, Xu Songzhou, Lin Yueyu. Effects of probiotics on feeding intolerance in low birth weight premature infants. CHINESE JOURNAL OF CONTEMPORARY PEDIATRICS. 2010;12(9):693-695.

33.Bian Jing YY. Clinical application value of probiotics in the prevention and treatment of feeding intolerance in very low birth weight premature infants. Hainan Medicine. 2016;27(20):3401-3403.

34.Li Juan LJ, He Liu. EFFECTS OF PROBIOTICS ON FEEDING INTOLERANCE IN PREMATURE INFANTS WITH VERY LOW WEIGHT. Chinese Journal of Coal Industry Medicine. 2013;16(8):1342-1344.

35.Wenhui. W. Clinical effect analysis of probiotics in preventing necrotizing enterocolitis in premature infants. Maternal \& Child Health Care of China. 2013;28(23):3793-3796.

36.Mo Guohuan LQ, Xie Yi. The role of probiotics in reducing feeding tolerance in very low birth weight preterm infants and low birth weight preterm infants. Strait Pharmaceutical Journal. 2017;29(10):114-115. 
37.Qinqin. S. Effect of prophylactic probiotic intervention on the risk of necrotizing enterocolitis in very low birth weight infants. Modern Diagnosis \& Treatment. 2018;29(18):2916-2918.

38.Xu Liangyin LZ. Risk factors for necrotizing enterocolitis in premature infants and observation on prophylactic effect of probiotics. Maternal \& Child Health Care of China. 2018;33(22):5150-5153.

39.Dani C, Biadaioli R, Bertini G, Martelli E, Rubaltelli FF. Probiotics feeding in prevention of urinary tract infection, bacterial sepsis and necrotizing enterocolitis in preterm infants. A prospective double-blind study. Biology of the neonate. Aug 2002;82(2):103-108.

40.Bin-Nun A, Bromiker $\mathrm{R}$, Wilschanski $\mathrm{M}$, et al. Oral probiotics prevent necrotizing enterocolitis in very low birth weight neonates. The Journal of pediatrics. Aug 2005;147(2):192-196.

41.Lin $\mathrm{HC}$, Su BH, Chen AC, et al. Oral probiotics reduce the incidence and severity of necrotizing enterocolitis in very low birth weight infants. Pediatrics. Jan 2005;115(1):1-4.

42.Manzoni P, Mostert M, Leonessa ML, et al. Oral supplementation with Lactobacillus casei subspecies rhamnosus prevents enteric colonization by Candida species in preterm neonates: a randomized study. Clinical infectious diseases: an official publication of the Infectious Diseases Society of America. Jun 15 2006;42(12):1735-1742.

43. Lin $\mathrm{HC}$, Hsu $\mathrm{CH}$, Chen $\mathrm{HL}$, et al. Oral probiotics prevent necrotizing enterocolitis in very low birth weight preterm infants: a multicenter, randomized, controlled trial. Pediatrics. Oct 2008;122(4):693-700.

44.Rouge $\mathrm{C}$, Piloquet $\mathrm{H}$, Butel $\mathrm{MJ}$, et al. Oral supplementation with probiotics in very-low-birth-weight preterm infants: a randomized, double-blind, placebo-controlled trial. The American journal of clinical nutrition. Jun 2009;89(6):1828-1835.

45.Mihatsch WA, Vossbeck S, Eikmanns B, Hoegel J, Pohlandt F. Effect of Bifidobacterium lactis on the incidence of nosocomial infections in very-low-birth-weight infants: a randomized controlled trial. Neonatology. 2010;98(2):156-163.

46.Sari FN, Dizdar EA, Oguz S, Erdeve O, Uras N, Dilmen U. Oral probiotics: Lactobacillus sporogenes for prevention of necrotizing enterocolitis in very low-birth weight infants: a randomized, controlled trial. European journal of clinical nutrition. Apr 2011;65(4):434-439.

47.Braga TD, da Silva GA, de Lira PI, de Carvalho Lima M. Efficacy of Bifidobacterium breve and Lactobacillus casei oral supplementation on necrotizing enterocolitis in very-low-birth-weight preterm infants: a double-blind, randomized, controlled trial. The American journal of clinical nutrition. Jan 2011;93(1):81-86.

48.Al-Hosni M, Duenas M, Hawk M, et al. Probiotics-supplemented feeding in extremely low-birth-weight infants. Journal of perinatology: official journal of the California Perinatal Association. Apr 2012;32(4):253259. 
49.Rojas MA, Lozano JM, Rojas MX, et al. Prophylactic probiotics to prevent death and nosocomial infection in preterm infants. Pediatrics. Nov 2012;130(5):e1113-1120.

50.Jacobs SE, Tobin JM, Opie GF, et al. Probiotic effects on late-onset sepsis in very preterm infants: a randomized controlled trial. Pediatrics. Dec 2013;132(6):1055-1062.

51.Demirel G, Erdeve O, Celik IH, Dilmen U. Saccharomyces boulardii for prevention of necrotizing enterocolitis in preterm infants: a randomized, controlled study. Acta paediatrica. Dec 2013;102(12):e560565 .

52.Serce O, Benzer D, Gursoy T, Karatekin G, Ovali F. Efficacy of Saccharomyces boulardii on necrotizing enterocolitis or sepsis in very low birth weight infants: a randomised controlled trial. Early human development. Dec 2013;89(12):1033-1036.

53.Fernandez-Carrocera LA, Solis-Herrera A, Cabanillas-Ayon M, et al. Double-blind, randomised clinical assay to evaluate the efficacy of probiotics in preterm newborns weighing less than $1500 \mathrm{~g}$ in the prevention of necrotising enterocolitis. Archives of disease in childhood. Fetal and neonatal edition. Jan 2013;98(1):F59.

54.Totsu S, Yamasaki C, Terahara M, Uchiyama A, Kusuda S, Probiotics Study Group in J. Bifidobacterium and enteral feeding in preterm infants: cluster-randomized trial. Pediatrics international: official journal of the Japan Pediatric Society. Oct 2014;56(5):714-719.

55.Oncel MY, Sari FN, Arayici S, et al. Lactobacillus Reuteri for the prevention of necrotising enterocolitis in very low birthweight infants: a randomised controlled trial. Archives of disease in childhood. Fetal and neonatal edition. Mar 2014;99(2):F110-115.

56.Saengtawesin V, Tangpolkaiwalsak R, Kanjanapattankul W. Effect of oral probiotics supplementation in the prevention of necrotizing enterocolitis among very low birth weight preterm infants. Journal of the Medical Association of Thailand = Chotmaihet thangphaet. Jun 2014;97 Suppl 6:S20-25.

57.Dilli D, Aydin B, Fettah ND, et al. The propre-save study: effects of probiotics and prebiotics alone or combined on necrotizing enterocolitis in very low birth weight infants. The Journal of pediatrics. Mar 2015;166(3):545-551 e541.

58. Hays S, Jacquot A, Gauthier $\mathrm{H}$, et al. Probiotics and growth in preterm infants: A randomized controlled trial, PREMAPRO study. Clinical nutrition. Aug 2016;35(4):802-811.

59. Costeloe K, Hardy P, Juszczak E, Wilks M, Millar MR, Probiotics in Preterm Infants Study Collaborative G. Bifidobacterium breve BBG-001 in very preterm infants: a randomised controlled phase 3 trial. Lancet. Feb 13 2016;387(10019):649-660.

60.Patole S, Keil AD, Chang A, et al. Effect of Bifidobacterium breve M-16V supplementation on fecal bifidobacteria in preterm neonates-a randomised double blind placebo controlled trial. PloS one. 2014;9(3):e89511. 
61.Xu L, Wang Y, Wang Y, et al. A double-blinded randomized trial on growth and feeding tolerance with Saccharomyces boulardii CNCM I-745 in formula-fed preterm infants. Jornal de pediatria. May-Jun 2016;92(3):296-301.

62.Chowdhury T, Ali MM, Hossain MM, et al. Efficacy of Probiotics Versus Placebo in the Prevention of Necrotizing Enterocolitis in Preterm Very Low Birth Weight Infants: A Double-Blind Randomized Controlled Trial. Journal of the College of Physicians and Surgeons-Pakistan: JCPSP. Sep 2016;26(9):770-774.

63.Guney-Varal I, Koksal N, Ozkan H, Bagci O, Dogan P. The effect of early administration of combined multistrain and multi-species probiotics on gastrointestinal morbidities and mortality in preterm infants: A randomized controlled trial in a tertiary care unit. The Turkish journal of pediatrics. 2017;59(1):13-19.

64.Kane AF, Bhatia AD, Denning PW, Shane AL, Patel RM. Routine Supplementation of Lactobacillus rhamnosus GG and Risk of Necrotizing Enterocolitis in Very Low Birth Weight Infants. The Journal of pediatrics. Apr 2018;195:73-79 e72.

65.Sharpe J, Way M, Koorts PJ, Davies MW. The availability of probiotics and donor human milk is associated with improved survival in very preterm infants. World journal of pediatrics: WJP. Oct 2018;14(5):492-497.

66.Uberos J, Aguilera-Rodriguez E, Jerez-Calero A, Molina-Oya M, Molina-Carballo A, Narbona-Lopez E. Probiotics to prevent necrotising enterocolitis and nosocomial infection in very low birth weight preterm infants. The British journal of nutrition. Apr 2017;117(7):994-1000.

67.Meyer MP, Alexander T. Reduction in necrotizing enterocolitis and improved outcomes in preterm infants following routine supplementation with Lactobacillus GG in combination with bovine lactoferrin. Journal of neonatal-perinatal medicine. 2017;10(3):249-255.

68.Ting. Z. Preventive effect of probiotics combined with early microfeeding on neonatal necrotizing enterocolitis. Clinical Medicine. 2018;38(1):103-105.

69.Guiqin. L. Analysis of the clinical effect of probiotics in preventing necrotizing enterocolitis in preterm infants. Journal of Shanxi Medical College for Continuing Education. 2017;27(6):30-32.

70.Liu Jumin LX, Gu Hailing. Impact of oral probiotics and early minimal enteral feeding on necrotizing enterocolitis in premature infants. Journal of Community Medicine. 2014;12(6):18-20.

71.Ni. Z. Therapeutic effect of oral probiotics on neonatal necrotizing enterocolitis. Chinese Journal of Ethnomedicine and Ethnopharmacy. 2012;21(1):81.

72.Xu Jiangshan WF, Kou Ran. Efficacy and safety of oral probiotics in preventing severe necrotizing enterocolitis in premature infants. The Journal of Medical Theory and Practice. 2017;30(14):2128-2129.

73.Wu Yanjun BL, Hua Ziyu. Effect of BB-12 plus LGG on the gastrointestinal function of very low birth weight preterm infants. Chinese Journal of Microecology. 2013;25(3):317-320. 
74.Wenyao. M. Clinical analysis of probiotics combined with early microfeeding to prevent neonatal necrotizing enterocolitis. Shenzhen Journal of Integrated Traditional Chinese and Western Medicine. 2014;24(5):106-107.

75.Huaxian. L. Analysis of the effect of probiotics combined with early microfeeding on prevention of neonatal necrotizing enterocolitis. Journal of Pediatric Pharmacy. 2013;19(6):18-20.

76.Wang Shaoqiang WQ. Clinical effects of probiotics in prevention of neonatal necrotizing enterocolitis. World Chinese Journal of Digestology. 2016;24(15):2406-2409.

77.Dongol Singh SS, Klobassa DS, Resch B, Urlesberger B, Shrestha RP. Placebo Controlled Introduction of Prophylactic Supplementation of Probiotics to Decrease the Incidence of Necrotizing Enterocolitis at Dhulikhel Hospital in Nepal. Kathmandu University medical journal. Oct.-Dec. 2017;15(60):319-323.

78.Panrong. N. Study on Clinical Curative Effect of Probiotics in Preventing the Necrotizing Enterocolitis in Premature Infants. World Journal of Complex Medicine. 2017;3(3):67-69.

79.Xiuli. W. Clinical observation of probiotics in preventing necrotizing enterocolitis in premature infants. Journal of Clinical Medical Literature (ElectronicEdition). 2017;4(83):16285-16286.

80.Jiangwen. L. Therapeutic effect of probiotics on NEC in low birth weight infants. The Journal of Medical Theory and Practice. 2013;26(10):1341-1342.

81.Deng Jianling CK. Early mininal feeding combined with probiotics to prevent necrotizing enterocolitis in preterm infant. CHINESE JOURNAL OF MODERN DRUG APPLICATION. 2010;4(6):13-14.

82.Jinlei. Z. Therapeutic effect of early prophylactic application of intestinal probiotics on necrotizing enterocolitis in preterm infants. Guide of China Medicine. 2014;12(29):123-125.

83.Xiaoyan. D. Effect of early prophylactic probiotics on necrotizing enterocolitis in low birth weight infants. Shaanxi Medical Journal. 2017;46(9):1178-1179.

84.Sawh SC, Deshpande S, Jansen S, Reynaert CJ, Jones PM. Prevention of necrotizing enterocolitis with probiotics: a systematic review and meta-analysis. PeerJ. 2016;4:e2429.

85.Zhu XL, Tang XG, Qu F, Zheng Y, Zhang WH, Diao YQ. Bifidobacterium may benefit the prevention of necrotizing enterocolitis in preterm infants: A systematic review and meta-analysis. International journal of surgery. Jan 2019;61:17-25.

86.Thomas JP, Raine T, Reddy S, Belteki G. Probiotics for the prevention of necrotising enterocolitis in very low-birth-weight infants: a meta-analysis and systematic review. Acta paediatrica. Nov 2017;106(11):17291741.

87.Sun J, Marwah G, Westgarth M, Buys N, Ellwood D, Gray PH. Effects of Probiotics on Necrotizing Enterocolitis, Sepsis, Intraventricular Hemorrhage, Mortality, Length of Hospital Stay, and Weight Gain in Very Preterm Infants: A Meta-Analysis. Advances in nutrition. Sep 2017;8(5):749-763. 
88.Ren YF, Wang LL. [Effects of probiotics on intestinal bacterial colonization in premature infants].

Zhongguo dang dai er ke za zhi = Chinese journal of contemporary pediatrics. Mar 2010;12(3):192-194.

89.Wang K, Tao G, Sylvester KG. Recent Advances in Prevention and Therapies for Clinical or Experimental Necrotizing Enterocolitis. Digestive diseases and sciences. Apr 152019.

90.Wu W, Wang Y, Zou J, et al. Bifidobacterium adolescentis protects against necrotizing enterocolitis and upregulates TOLLIP and SIGIRR in premature neonatal rats. BMC pediatrics. Jan 5 2017;17(1):1.

91.Ling X, Linglong P, Weixia D, Hong W. Protective Effects of Bifidobacterium on Intestinal Barrier Function in LPS-Induced Enterocyte Barrier Injury of Caco-2 Monolayers and in a Rat NEC Model. PloS one. 2016;11(8):e0161635.

92.Gomez-Rodriguez G, Amador-Licona N, Daza-Benitez L, et al. Single strain versus multispecies probiotic on necrotizing enterocolitis and faecal IgA levels in very low birth weight preterm neonates: A randomized clinical trial. Pediatrics and neonatology. Mar 22019.

\section{Tables}

Table 1. Baseline characteristics of qualified studies in this meta-analysis. 


\begin{tabular}{|c|c|c|c|c|c|c|c|c|c|}
\hline Author & Year & Country & $\begin{array}{c}\text { Probiotic } \\
\text { composition }\end{array}$ & $\begin{array}{l}\text { NEC } \\
\text { stage } \geq 2 \\
\text { in } \\
\text { probiotic } \\
\text { group, } \\
(\%)\end{array}$ & $\begin{array}{l}\text { NEC } \\
\text { stage } \geq \\
2 \text { in } \\
\text { control } \\
\text { group, } \\
(\%)\end{array}$ & $\begin{array}{l}\text { All cause } \\
\text { mortality } \\
\text { in } \\
\text { probiotic } \\
\text { group, } \\
\text { (\%) }\end{array}$ & $\begin{array}{l}\text { All-cause } \\
\text { mortality } \\
\text { in control } \\
\text { group, } \\
(\%)\end{array}$ & $\begin{array}{l}\text { NEC- } \\
\text { related } \\
\text { mortality } \\
\text { in } \\
\text { probiotic } \\
\text { group, } \\
(\%) \\
\end{array}$ & $\begin{array}{l}\text { NEC- } \\
\text { related } \\
\text { mortality } \\
\text { in } \\
\text { control } \\
\text { group, } \\
(\%) \\
\end{array}$ \\
\hline Dani & 2002 & Italy & LRh & $4 / 295$ & $8 / 290$ & $0 / 295$ & $2 / 290$ & $2 / 295$ & $0 / 290$ \\
\hline Costalos & 2003 & Greece & SB & $5 / 51$ & $6 / 36$ & & & & \\
\hline Bin-Nun & 2005 & Israel & Bbi, BI, ST & $1 / 72$ & $10 / 73$ & $3 / 72$ & $8 / 73$ & $0 / 72$ & $3 / 73$ \\
\hline Lin & 2005 & China & $\mathrm{LA}, \mathrm{BI}$ & $2 / 180$ & $10 / 187$ & $7 / 180$ & $20 / 187$ & & \\
\hline Manzoni & 2006 & Italy & LRh & $1 / 39$ & $3 / 41$ & $5 / 39$ & $6 / 41$ & & \\
\hline Stratiki & 2007 & Ireland & BLa & $0 / 41$ & $3 / 34$ & & & & \\
\hline Samanta & 2008 & India & $\begin{array}{l}\text { BI, BBi, } \\
\text { BLo, LA }\end{array}$ & $5 / 91$ & $15 / 95$ & $4 / 91$ & $14 / 95$ & & \\
\hline Lin & 2008 & Taiwan & BBi, LA & $4 / 217$ & $14 / 217$ & $2 / 217$ & $9 / 217$ & $2 / 217$ & $3 / 217$ \\
\hline Rouge & 2009 & Spain & LRh, BLo & $2 / 45$ & $1 / 49$ & $4 / 49$ & $2 / 45$ & & \\
\hline Samanta & 2009 & UK & BI, LA & $5 / 91$ & $15 / 95$ & $4 / 91$ & $14 / 95$ & & \\
\hline Manzoni & 2009 & Italy & $\mathrm{LRh}$ & $0 / 151$ & $3 / 153$ & $6 / 151$ & $4 / 153$ & & \\
\hline Mark & 2009 & US & $\begin{array}{l}\text { LA, BLo, } \\
\text { BLa }\end{array}$ & $1 / 31$ & $2 / 29$ & & & & \\
\hline Underwood & 2009 & US & LA & $1 / 30$ & $1 / 29$ & & & & \\
\hline Underwood & 2009 & US & LA, BLa & $1 / 31$ & $1 / 29$ & & & & \\
\hline Mihatsch & 2010 & Germany & $\mathrm{BLa}$ & $2 / 91$ & $4 / 89$ & $2 / 91$ & $1 / 89$ & $1 / 91$ & $0 / 89$ \\
\hline Chou & 2010 & US & BLa, LA & $0 / 153$ & $2 / 148$ & $8 / 153$ & $24 / 148$ & & \\
\hline $\mathrm{Hu}$ & 2010 & China & $\begin{array}{l}\text { BLa, LRb, } \\
\text { ST }\end{array}$ & $0 / 30$ & $1 / 30$ & & & & \\
\hline Hikaru & 2010 & US & $\mathrm{BLa}$ & & & $0 / 108$ & $4 / 100$ & & \\
\hline Deng & 2010 & China & $\begin{array}{l}\text { BLa, LA, } \\
\text { ETf }\end{array}$ & $1 / 62$ & $8 / 62$ & & & & \\
\hline Sari & 2011 & Turkey & LS & $6 / 110$ & 10/111 & $3 / 110$ & $4 / 111$ & $0 / 110$ & $1 / 111$ \\
\hline Braga & 2011 & Brazil & $\mathrm{LC}, \mathrm{BBr}$ & $0 / 119$ & $4 / 112$ & $26 / 119$ & $27 / 112$ & & \\
\hline Al-Hosni & 2012 & US & LRh, BI & $2 / 50$ & $2 / 51$ & $3 / 50$ & $4 / 50$ & & \\
\hline Rojas & 2012 & Columbia & LRe & $6 / 176$ & $10 / 194$ & & & & \\
\hline Zhou & 2012 & China & $\begin{array}{l}\text { BLa, LA, } \\
\text { ET, BC }\end{array}$ & $3 / 75$ & $7 / 50$ & & & & \\
\hline Jacobs & 2013 & Australia & Bl, ST, BLa & $11 / 548$ & 24/551 & $27 / 548$ & $28 / 551$ & $4 / 548$ & $11 / 551$ \\
\hline Demirel & 2013 & Turkey & SB & 6/135 & 7/136 & $5 / 135$ & $5 / 136$ & & \\
\hline Serce & 2013 & Turkey & SB & $7 / 104$ & $7 / 104$ & $5 / 104$ & $4 / 104$ & $3 / 104$ & $3 / 104$ \\
\hline $\begin{array}{l}\text { Fernandez- } \\
\text { Carrocera }\end{array}$ & 2013 & Mexico & $\begin{array}{l}\text { LA, LRh, } \\
\text { LC, LP, BI, } \\
\text { ST }\end{array}$ & $6 / 75$ & $12 / 75$ & $1 / 75$ & $7 / 75$ & & \\
\hline Wang & 2013 & China & BLa, LA & $1 / 120$ & $17 / 120$ & $16 / 120$ & $0 / 120$ & $5 / 120$ & $0 / 120$ \\
\hline Liao & 2013 & China & $\begin{array}{l}\text { BLo, LA, } \\
\text { ETf }\end{array}$ & $0 / 61$ & $3 / 61$ & & & & \\
\hline $\mathrm{Li}$ & 2013 & China & $\mathrm{BLa}$ & $0 / 15$ & $2 / 15$ & & & & \\
\hline $\mathrm{Wu}$ & 2013 & China & BLa, LRh & $3 / 45$ & $12 / 52$ & $2 / 45$ & $4 / 52$ & $0 / 45$ & $3 / 52$ \\
\hline Lin & 2013 & China & BS, ETf & $0 / 65$ & $4 / 55$ & & & & \\
\hline $\mathrm{Lu}$ & 2013 & China & NS & $2 / 84$ & $9 / 84$ & & & & \\
\hline Totsu & 2014 & Japan & $\mathrm{BBi}$ & $0 / 153$ & $0 / 130$ & $0 / 130$ & $2 / 153$ & & \\
\hline Patole & 2014 & Australia & $\mathrm{BBr}$ & $0 / 77$ & $1 / 76$ & $0 / 76$ & $0 / 77$ & & \\
\hline Oncel & 2014 & Turkey & $\mathrm{LRe}$ & $8 / 200$ & $10 / 200$ & $15 / 200$ & $15 / 200$ & $3 / 200$ & $4 / 200$ \\
\hline Saengtawesin & 2014 & Thailand & BBi, LA & $1 / 31$ & $1 / 29$ & $0 / 29$ & $0 / 31$ & $0 / 29$ & $0 / 31$ \\
\hline Zeng & 2014 & China & $\begin{array}{l}\text { BLa, LA, } \\
\text { ETf }\end{array}$ & $2 / 65$ & $9 / 63$ & & & & \\
\hline $\mathrm{Li}$ & 2014 & China & $\begin{array}{l}\text { BLa, LA, } \\
\text { ETf }\end{array}$ & $2 / 46$ & $10 / 46$ & & & $1 / 46$ & $4 / 46$ \\
\hline Manzoni & 2014 & Ireland & $\mathrm{LRh}$ & $0 / 238$ & $5 / 247$ & $18 / 238$ & $15 / 247$ & $9 / 238$ & $10 / 247$ \\
\hline Liu & 2014 & China & $\begin{array}{l}\text { BLa, LA, } \\
\text { ETf }\end{array}$ & $1 / 45$ & $5 / 45$ & & & & \\
\hline Maо & 2014 & China & $\mathrm{BS}, \mathrm{ETf}$ & $1 / 44$ & $6 / 44$ & & & & \\
\hline Zhang & 2014 & China & $\mathrm{CB}, \mathrm{BLa}$ & 1/115 & $5 / 115$ & & & $0 / 115$ & $1 / 115$ \\
\hline
\end{tabular}




\begin{tabular}{|c|c|c|c|c|c|c|c|c|c|}
\hline Dilli & 2015 & Turkey & $\mathrm{BLa}$ & $2 / 100$ & $18 / 100$ & $3 / 100$ & $12 / 100$ & & \\
\hline Hays & 2015 & France & BLa, BLo & $8 / 145$ & $3 / 52$ & $1 / 52$ & $5 / 145$ & & \\
\hline Kanic & 2015 & Germany & Bla, LA, ETf & $0 / 40$ & $5 / 40$ & $2 / 40$ & $3 / 40$ & & \\
\hline Van Niekerk & 2015 & UK & LRh, BI & $1 / 54$ & $4 / 56$ & $2 / 54$ & $5 / 56$ & $0 / 54$ & $3 / 56$ \\
\hline Costeloe & 2016 & UK & $\mathrm{BBr}$ & $61 / 650$ & $66 / 660$ & $54 / 650$ & $56 / 660$ & $9 / 650$ & $14 / 660$ \\
\hline Bian & 2016 & China & BLa & $0 / 20$ & $1 / 19$ & & & & \\
\hline Costeloe & 2016 & England & $\mathrm{BBr}$ & $47 / 724$ & $58 / 462$ & $24 / 724$ & $33 / 462$ & & \\
\hline hays & 2016 & France & BLa & $2 / 50$ & $3 / 52$ & & & & \\
\hline hays & 2016 & France & BLo & $1 / 48$ & $3 / 52$ & & & & \\
\hline hays & 2016 & France & BLa, BLo & $5 / 47$ & $3 / 52$ & & & & \\
\hline $\mathrm{Xu}$ & 2016 & China & CD & $0 / 51$ & $0 / 49$ & & & & \\
\hline Chowdhury & 2016 & UK & BLa, LA & $1 / 52$ & $6 / 50$ & & & & \\
\hline Wang & 2016 & China & BS, ET & $2 / 70$ & $10 / 70$ & & & & \\
\hline Mo & 2017 & China & BLa & $0 / 21$ & $0 / 20$ & & & & \\
\hline Güney-Varal & 2017 & Turkey & $\begin{array}{l}\text { LRh, LC, } \\
\mathrm{LP}, \mathrm{BBa}\end{array}$ & $0 / 70$ & $4 / 40$ & $1 / 70$ & $9 / 40$ & $0 / 70$ & $3 / 40$ \\
\hline Uberos & 2017 & Spain & LRh & $2 / 53$ & $16 / 175$ & $2 / 33$ & $34 / 175$ & & \\
\hline Uberos & 2017 & Spain & BBi, LA & $2 / 33$ & 16/175 & $0 / 33$ & $34 / 175$ & & \\
\hline Meyer & 2017 & $\begin{array}{l}\text { New } \\
\text { Zealand }\end{array}$ & $\begin{array}{l}\text { LA and } \\
\text { lactoferrin }\end{array}$ & $4 / 396$ & $15 / 439$ & $39 / 396$ & $36 / 439$ & & \\
\hline $\mathrm{Li}$ & 2017 & China & $\begin{array}{l}\text { BLa, LA, } \\
\text { ETf }\end{array}$ & $1 / 10$ & $3 / 10$ & & & & \\
\hline $\mathrm{Xu}$ & 2017 & China & $\begin{array}{l}\text { BLa, LRb, } \\
\text { ST }\end{array}$ & $4 / 90$ & $9 / 90$ & & & & \\
\hline Singh & 2017 & Austria & $\mathrm{LRh}$ & $6 / 37$ & $10 / 35$ & & & & \\
\hline $\mathrm{Nie}$ & 2017 & China & $\begin{array}{l}\text { BLa, LA, } \\
\text { ETf, BC }\end{array}$ & $1 / 57$ & $7 / 57$ & $0 / 57$ & $4 / 57$ & & \\
\hline Wen & 2017 & China & $\begin{array}{l}\text { BLa, LRb, } \\
\text { ST }\end{array}$ & $1 / 35$ & $7 / 35$ & & & & \\
\hline Ding & 2017 & China & $\begin{array}{l}\text { BLa, LRb, } \\
\text { ST }\end{array}$ & $1 / 31$ & $5 / 39$ & $0 / 31$ & $2 / 39$ & & \\
\hline Deng & 2018 & China & $\begin{array}{l}\text { BLa, LA, } \\
\text { ETf }\end{array}$ & $2 / 102$ & $10 / 100$ & & & & \\
\hline Shi & 2018 & China & CB & $3 / 48$ & $9 / 42$ & & & & \\
\hline $\mathrm{Xu}$ & 2018 & China & BS, ETf & $9 / 247$ & 15/191 & & & & \\
\hline Kane & 2018 & US & LRh & 33/197 & $45 / 443$ & 13/197 & $17 / 443$ & & \\
\hline Sharpe & 2018 & Australia & NS & $7 / 457$ & $37 / 1334$ & $11 / 457$ & $101 / 1334$ & & \\
\hline Zhang & 2018 & China & BS, ETf & $1 / 40$ & $3 / 40$ & & & & \\
\hline
\end{tabular}

Note: LA, Lactobacillus acidophilus; BLa, Bifidobacterium lactis; BI, Bifidobacterium infantis; BBr, Bifidobacterium breve; BBi, Bifidobacterium bifidum; BBa, Bifidobacterium animalis; BLo, Bifidobacterium longum; LRb, Lactobacillus bulgaricus; LRh, Lactobacillus rhamnosus; ST, Streptococcus thermophiles; LRe, Lactobacillus reuteri; LC, Lactobacillus casei; ET, Enterococcus; ETf, Enterococcus faecalis; BS, Bacillus subtilis; CB, Clostridium butyricum; BC, Bacillus cereus; CB, Clostridium butyricum; CD, Clostridium difficile; SB, Saccharomyces boulardii; NS, Not stated in original study. 
Table 2. Summarized RRs with 95\% CIs for the association between probiotics and NEC, overall mortality, and NECrelated mortality.

\begin{tabular}{lcccccc}
\hline Pooled analysis & $\mathrm{n}$ & $\mathrm{RR}$ & $95 \% \mathrm{CI}$ & $\mathrm{p}_{\mathrm{z}}$ & $\mathrm{I}^{2}(\%)$ & $\mathrm{p}_{\mathrm{h}}$ \\
\hline NEC incidence & 70 & 0.435 & $0.357-0.530$ & $<0.001$ & 32.5 & 0.006 \\
\hline All cause mortality & 38 & 0.630 & $0.491-0.808$ & $<0.001$ & 52.0 & $<0.001$ \\
\hline NEC-related mortality & 16 & 0.639 & $0.423-0.966$ & 0.034 & 0.0 & 0.525 \\
\hline
\end{tabular}

Note: $\mathrm{n}$, the number of studies; $p_{\mathrm{z}}, p$ value for association test; $p_{\mathrm{h}}, p$ value for heterogeneity test.

\section{Figures}




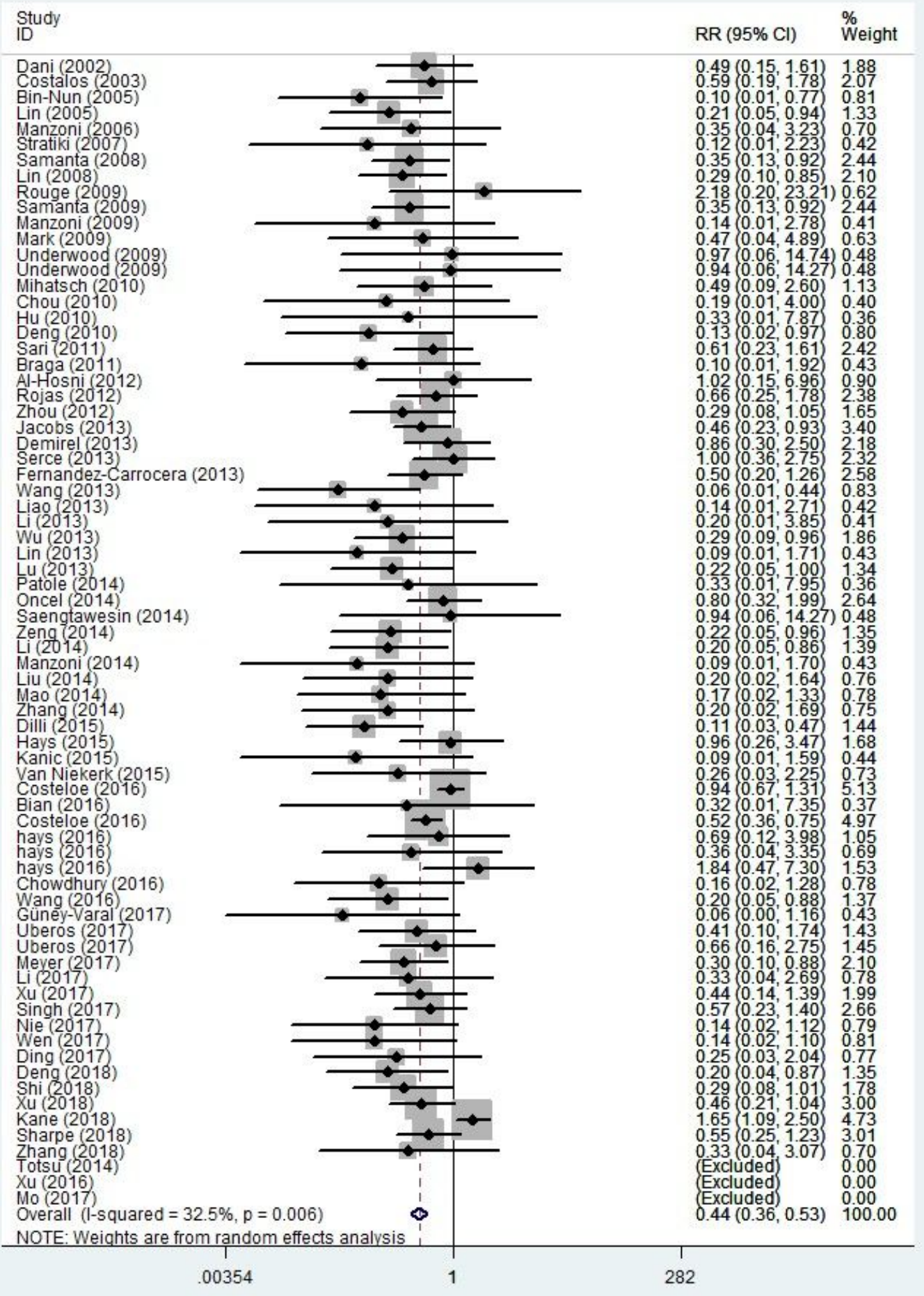

Figure 1

Forest plot of the association between probiotics and NEC under random model. 


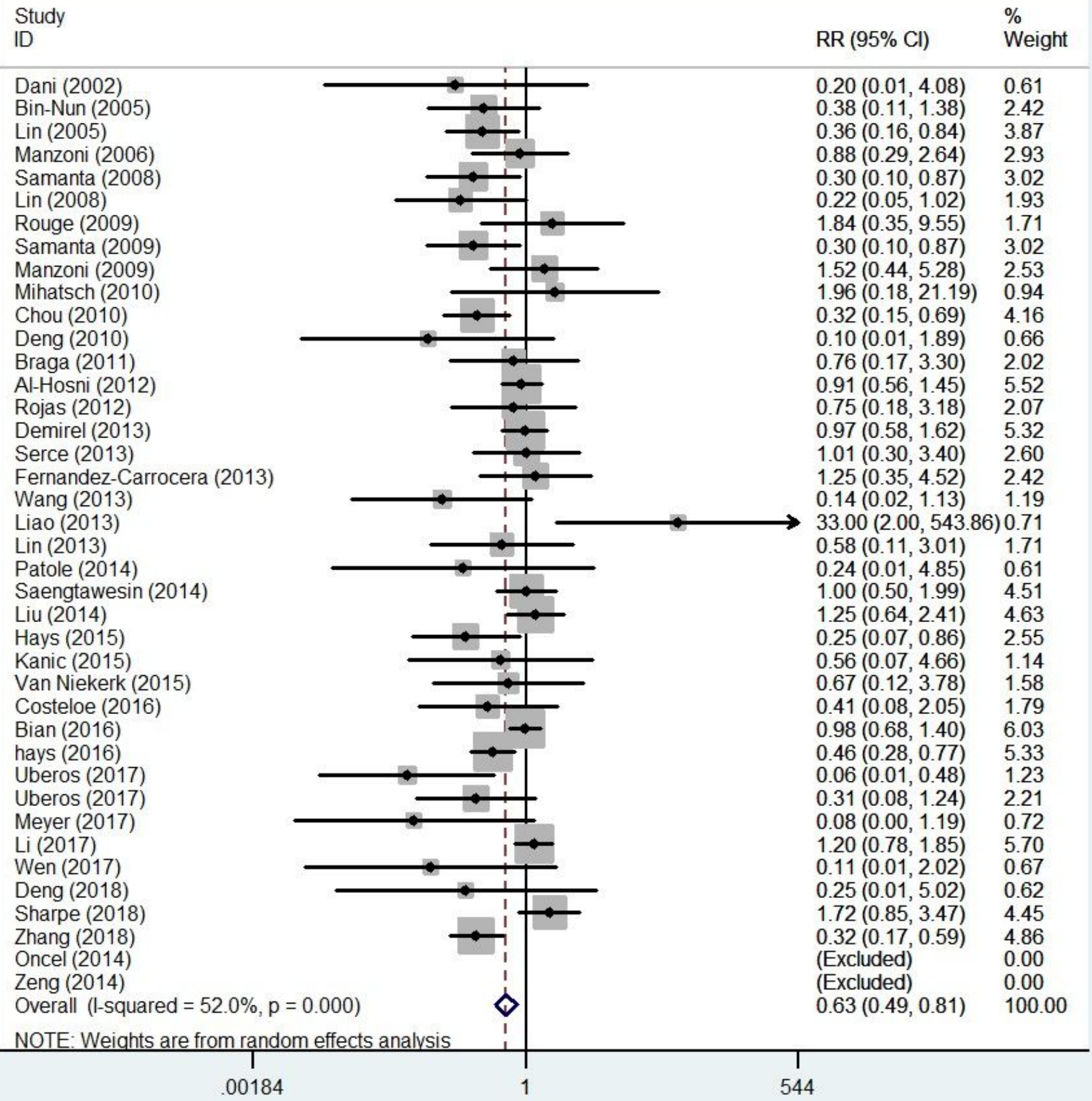

\section{Figure 2}

Forest plot of the association between probiotics and overall mortality under random model. 
Study

ID
$\mathrm{RR}(95 \% \mathrm{Cl})$
$\%$

Weight

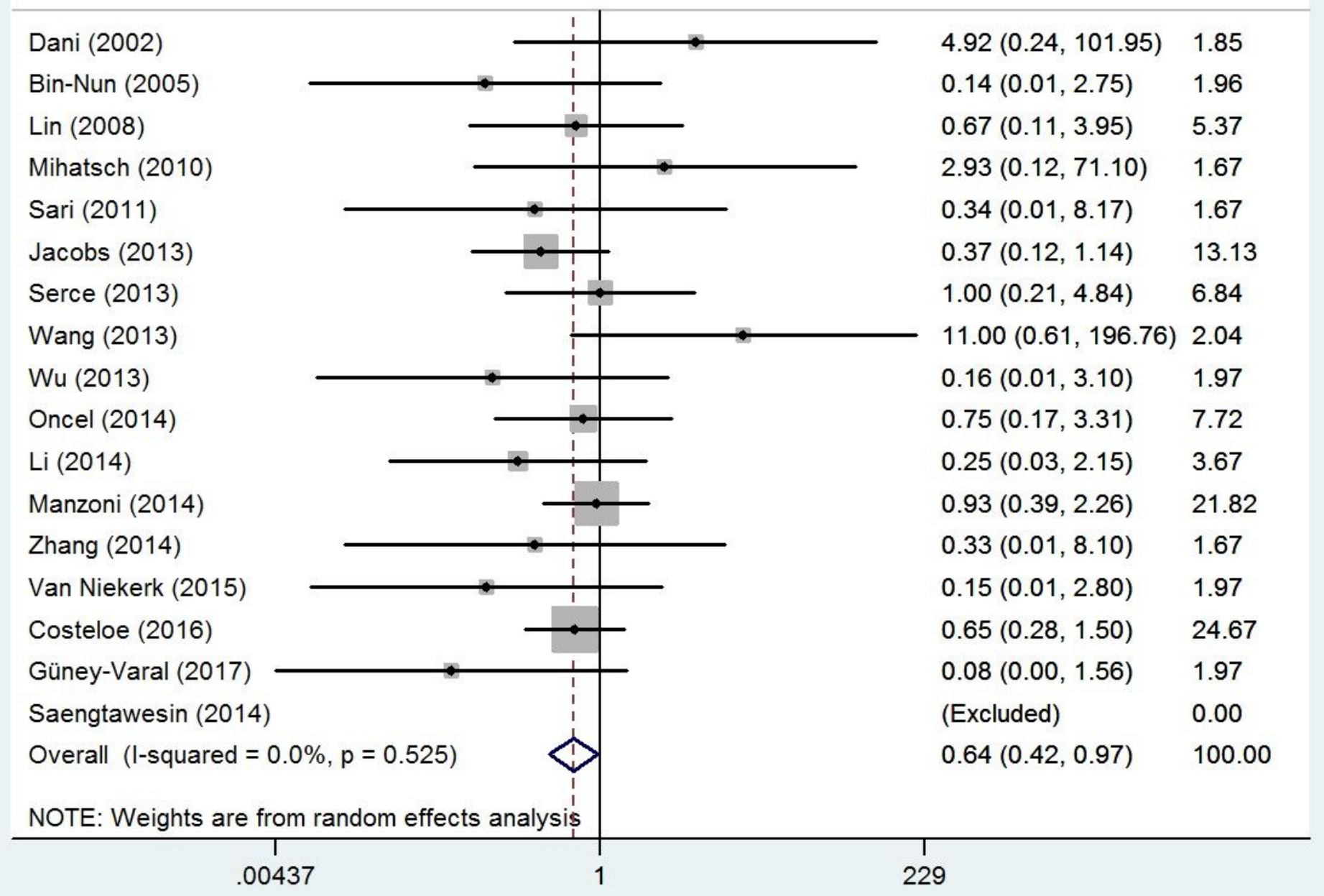

\section{Figure 3}

Forest plot of the association between probiotics and NEC-related mortality under random model. 
Funnel plot with pseudo $95 \%$ confidence limits

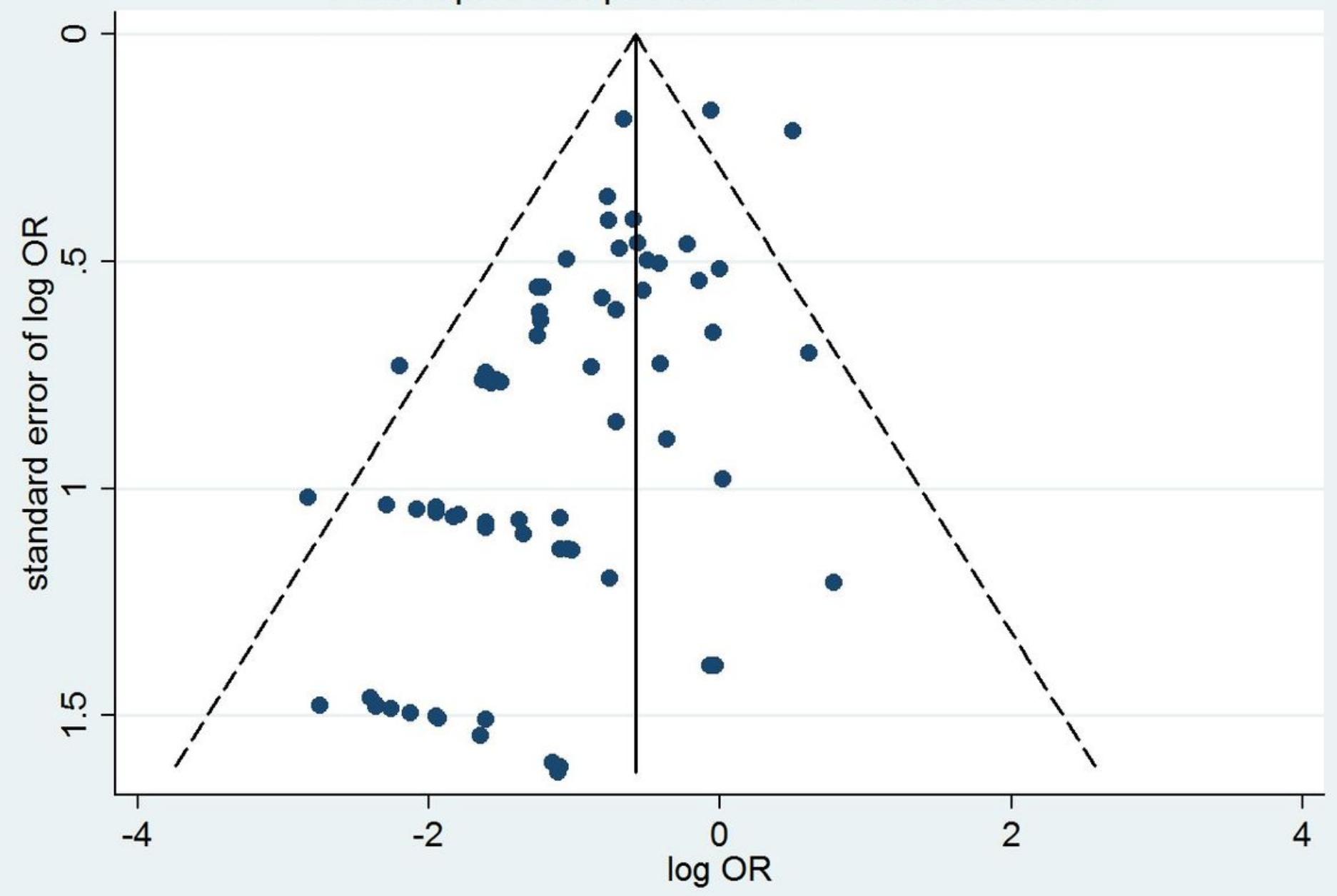

Figure 4

Funnel plot analysis on the detection of publication bias in the association between probiotics and NEC. 
Funnel plot with pseudo $95 \%$ confidence limits

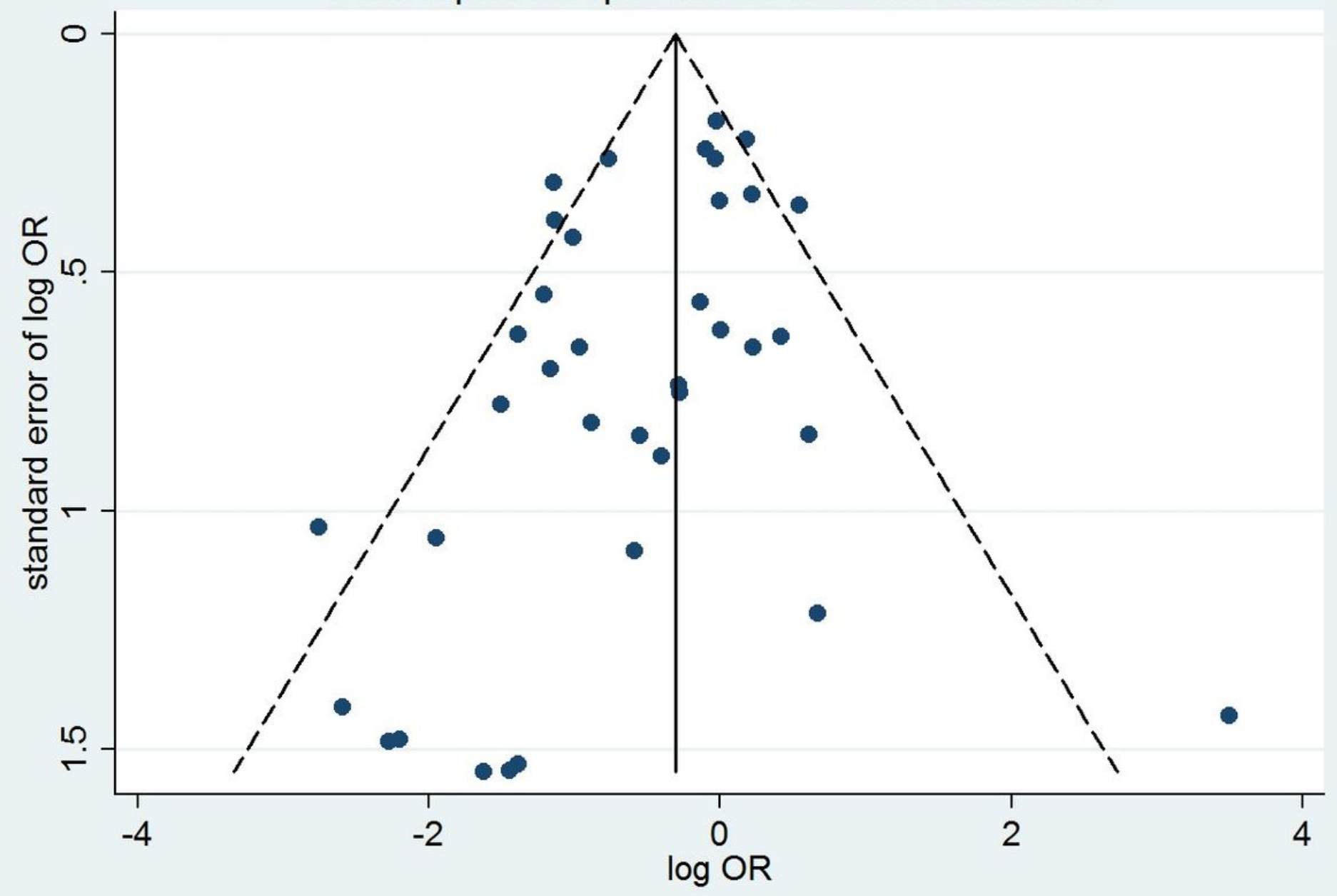

Figure 5

Funnel plot analysis on the detection of publication bias in the association between probiotics and overall mortality. 


\section{Funnel plot with pseudo 95\% confidence limits}

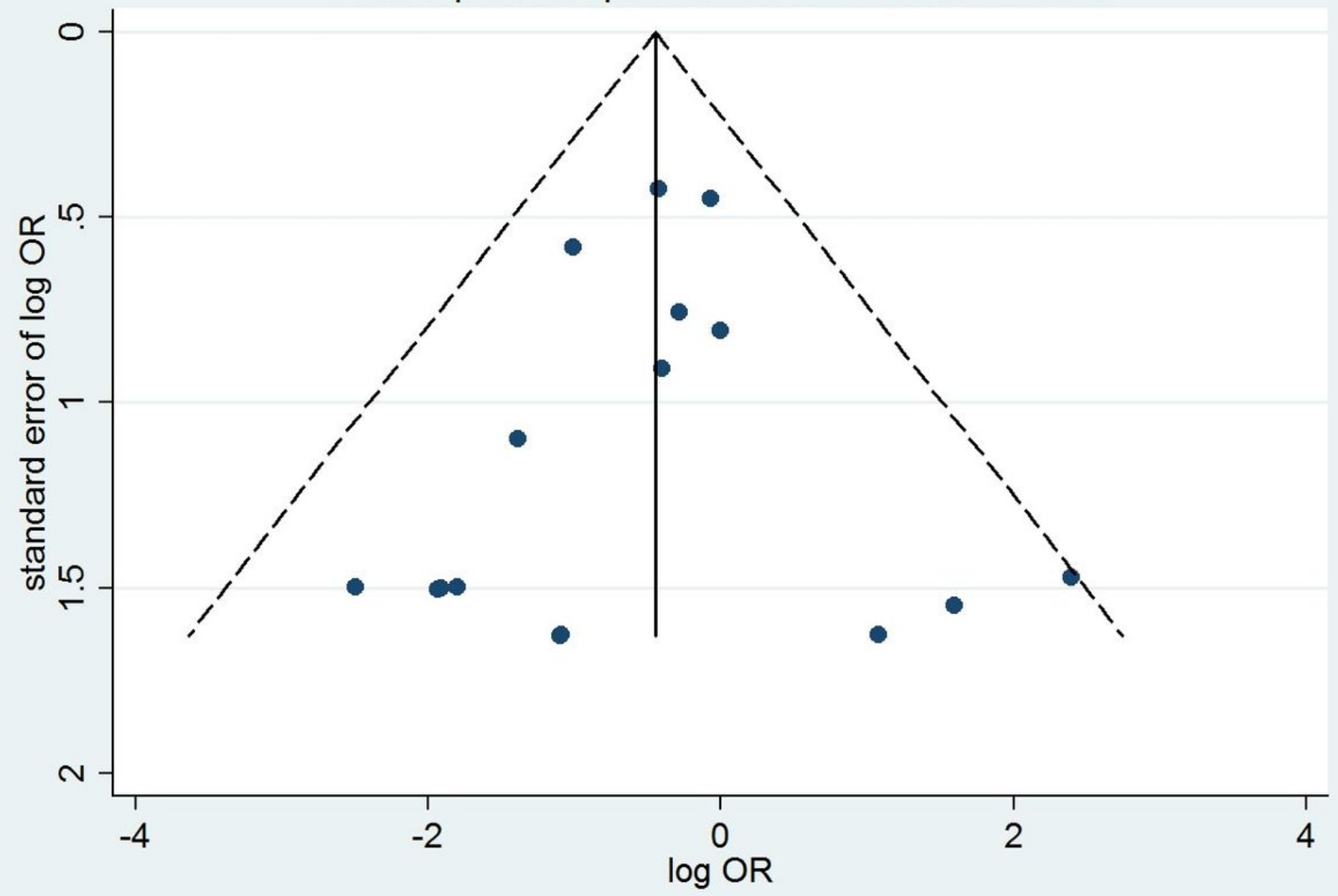

Figure 6

Funnel plot analysis on the detection of publication bias in the association between probiotics and NECrelated mortality.

\section{Supplementary Files}

This is a list of supplementary files associated with this preprint. Click to download.

- PRISMAflowdiagram.doc

- PRISMAchecklist.docx 